\title{
Prospective study to assess the obstetric and perinatal outcome in fibroid complicating pregnancy
}

\author{
Shalaka Dilip Mhatre*, Ayushi Vazirani, Vidhya Selvam
}

Department of Obstetrics and Gynecology, Sree Balaji Medical College and Hospital, Chennai Tamil Nadu, India

Received: 07 January 2021

Accepted: 09 February 2021

\author{
*Correspondence: \\ Dr. Shalaka Dilip Mhatre, \\ E-mail: mhatreshalaka1494@gmail.com
}

Copyright: (C) the author(s), publisher and licensee Medip Academy. This is an open-access article distributed under the terms of the Creative Commons Attribution Non-Commercial License, which permits unrestricted non-commercial use, distribution, and reproduction in any medium, provided the original work is properly cited.

\begin{abstract}
Background: Fibroids are the most common benign tumour of the uterus. Complications ranges from approximately $10-40 \%$ in fibroid complicating pregnancy. The objective of the study was to assess obstetric and perinatal outcomes in fibroid complicating pregnancy.

Methods: A prospective study was carried out over a period of 01 June 2019-30 October 2020 on 42 women diagnosed with fibroid uterus in pregnancy. The study was conducted in the Obstetrics and Gynaecology department of Sree Balaji Medical College and Hospital, Chennai. Routine basic investigations were done. Ultrasonogram was done at booking visit and during subsequent visits to assess the increase in the size of the fibroid and degeneration and other obstetric complications such as malpresentation and placenta previa.

Results: Major proportion was in the younger age group of 25-35 years. Fibroids were more frequent in multigravidae $34(80.96 \%)$, and primigravidae were $8(19.04 \%)$. The reported incidence of fibroid in pregnancy ranges from $0.01 \%-10.7 \%$. $27(64.28 \%)$ women were asymptomatic during pregnancy. Out of 42 women, 10 $(23.80 \%)$ were known cases of fibroid became pregnant, remaining $32(76.19 \%)$ were diagnosed as having fibroid during routine antenatal visits. 2 women $(22.22 \%)$ had pain, 3 of them $(7.14 \%)$ had preterm labor, $3(7.14 \%)$ had spontaneous miscarriage, 6 (14.2) had threatened abortion, and 1(2.3\%) had abruption placentae and $1(2.5 \%)$ had placenta previa. Out of 39, $27(69.23 \%)$ women had vaginal delivery of which $2(7.40 \%)$ women had assisted vaginal delivery. Lower segment cesarean section done in 12 women (30.76\%). 32 babies delivered (82.05\%) appropriate for gestational age infants, 3 (7.69\%) had LBW, and 4 (10.25\%) were IUGR.

Conclusions: Fibroid complicating pregnancy are associated with complications during the antepartum, intrapartum, and postpartum period hence a regular follow up and evaluation is a must. Most pregnancies with fibroids are asymptomatic but may adversely affect the obstetric and perinatal outcome.
\end{abstract}

Keywords: Fibroids, Myomas, Pregnancy

\section{INTRODUCTION}

Fibroids (leiomyomas) are the most frequently recorded benign smooth muscle tumor of the uterus, affecting $20 \%-60 \%$ of women of reproductive age and may negatively affect fertility and outcome of pregnancy. ${ }^{1}$ As most fibroids are asymptomatic, the true prevalence of fibroids may be greatly higher. The incidence of fibroids in pregnancy reported ranges from 0.1 to $10.7 \%$ of all pregnancies and increases as the female chooses to postpone pregnancy later on. ${ }^{1-3}$ Most of the women detected with fibroid have uneventful pregnancies, however $10-28 \%$ of them may present with certain complications. $^{4,5}$

\section{METHODS}

The present study was a prospective study carried out over a period of 16 months on 42 women diagnosed with fibroid uterus in pregnancy. The study period was from 01 June 2019-30 October 2020 and was conducted in the Obstetrics and Gynaecology department of Sree Balaji 
Medical College and Hospital, Chennai. Women with fibroid complicating pregnancy were included in the study. The mean age group was 29.8 years. In our study, 8 were primigravidae and were 34 multigravidae. Out of the study population, 3 women were with large fibroid more than $10 \mathrm{~cm}$ and others were with fibroids of between 3-7 cm. 10 were known cases of fibroid and others were diagnosed during their antenatal visits.

\section{RESULTS}

Myomas are the most common benign smooth muscle tumours of the uterus. They have been found to be associated with pain, degeneration and can affect pregnancy outcome. In our study, we included 42 women who were having pregnancy with uterine fibroids. A major proportion was in the younger age group of 25-35 years (Table 1).

Table 1: Age of study population $(n=42)$.

\begin{tabular}{|lll|}
\hline Age in years & $\mathbf{n = 4 2}$ & Percentage \\
\hline $\mathbf{2 0 - 2 4}$ & 06 & 14.2 \\
\hline $\mathbf{2 5 - 3 0}$ & 17 & 40.4 \\
\hline $\mathbf{3 1 - 3 5}$ & 15 & 35.7 \\
\hline $\mathbf{3 6}$ & 04 & 9.5 \\
\hline
\end{tabular}

Table 2: Parity wise distribution $(n=42)$.

\begin{tabular}{|lll|}
\hline Gravidity & $\mathbf{n = 4 2}$ & Percentage \\
\hline Primiparity & 8 & 19.04 \\
\hline Multiparity & 34 & 80.95 \\
\hline
\end{tabular}

Table 3: Duration of gestation at diagnosis $(n=42)$.

\begin{tabular}{|lll|}
\hline Gestational age (weeks) & n=42 & Percentage \\
\hline Pre pregnancy & 12 & 28.5 \\
\hline $\mathbf{1 2}$ & 18 & 42.8 \\
\hline $\mathbf{1 3}$ - 20 & 05 & 11.9 \\
\hline $\mathbf{2 1}-\mathbf{2 8}$ & 04 & 9.5 \\
\hline $\mathbf{2 9}$ - 36 & 03 & 7.1 \\
\hline
\end{tabular}

The mean age in our study population was 29.8 years. Fibroids were more frequent in multigravidae 34 $(80.96 \%)$, and primigravidae were $8(19.04 \%)$ (Table 2$)$.

Table 4: Complications during pregnancy $(n=42)$.

\begin{tabular}{|lll|}
\hline Complication & $\mathbf{n = 4 2}$ & Percentage \\
\hline Asymptomatic & 27 & 64.28 \\
\hline Spontaneous abortion & 03 & 7.14 \\
\hline Pain abdomen & 02 & 22.22 \\
\hline Threatened abortion & 07 & 16.6 \\
\hline Threatened PTL & 03 & 7.14 \\
\hline Anemia & 04 & 9.5 \\
\hline
\end{tabular}

PPH: postpartum hemorrhage; PTL: preterm labour
The reported incidence of fibroid in pregnancy ranges from $0.01 \%$ to $10.7 \%$. $16(38.09 \%)$ women were asymptomatic during pregnancy. $2(22.2 \%)$ women had pain, $7(16.6 \%)$ of them had threatened abortion, 3 (7.4\%) had spontaneous miscarriage, and 1 (2.3\%) had abruption placentae, and placenta previa was diagnosed in $1(2.5 \%)$ patient (Table 4$)$. Out of 39, $27(69.23 \%)$ women had a vaginal delivery, out of which $2(7.4 \%)$ had assisted vaginal delivery. Lower segment cesarean section (LSCS) done in 12 (30.7\%) (Table 5). Indications for- LSCS were breech presentation in 3 (7.69\%) women, placenta previa in $1(2.5 \%)$, abruption placentae in 1 (2.5\%), non-progressive labor in 2 (5.12\%), malpresentation in $3(7.69 \%), 1(2.56 \%)$ had fetal distress and, CPD in $1(2.56 \%)$ (Table 6$)$. In our study neonatal outcome was, $32(82.05 \%)$ resulted in appropriate for gestational age infants, and $3(7.69 \%)$ were LBW, and 4 (10.25\%) had IUGR (Table 7).

Table 5: Mode of delivery $(n=39)$.

\begin{tabular}{|lll|}
\hline Mode of delivery & $\mathbf{n}=\mathbf{3 9}$ & Percentage \\
\hline SVD & 27 & 69.23 \\
\hline LSCS & 12 & 30.7 \\
\hline
\end{tabular}

SVD: spontaneous vaginal delivery; LSCS: lower segment cesarean section

Table 6: Indication for $\operatorname{LSCS}(\mathrm{n}=12)$.

\begin{tabular}{|lll|}
\hline Cesarean section & $\mathbf{n = 1 2}$ & Percentage \\
\hline Breech & 01 & 2.56 \\
\hline Previous LSCS & 02 & 5.12 \\
\hline Placenta previa & 01 & 2.56 \\
\hline Malpresentation & 03 & 7.69 \\
\hline Fetal distress & 01 & 2.56 \\
\hline CPD & 01 & 2.56 \\
\hline Non progressive labour & 02 & 5.12 \\
\hline Abruptio placentae & 01 & 2.56 \\
\hline
\end{tabular}

CPD: Cephalo pelvic disproportion

Table 7: Neonatal outcomes.

\begin{tabular}{|lll|}
\hline Outcome & $\mathbf{n = 3 9}$ & Percentage \\
\hline AGA & 32 & 82.05 \\
\hline LBW & 03 & 7.69 \\
\hline IUGR & 04 & 10.25 \\
\hline
\end{tabular}

AGA: Appropriate for gestational age; LBW: Low birth weight; IUGR: Intrauterine growth restriction

\section{DISCUSSION}

We have conducted this study to assess the maternal and fetal outcome in fibroid complicating pregnancy. Mean maternal age in our study was found to be 29.8 years, which is comparable to other studies, showing occurrence of leiomyomas in second and third decades of life.

In our study, we found that fibroids were less frequent in primigravidae compared to multigravidae, which is 
consistent with study conducted by Poovathi et al $(73.3 \%$ multigravida and $26.6 \%$ primigravidae). ${ }^{5}$ This is inconsistent with earlier studies by Sarwar et al $(63 \%$ multigravida and $37 \%$ primigravidae). ${ }^{3}$ Regarding obstetric complications, in our study, 3 out of 42 patients (7.14) had a spontaneous abortion. High incidence of abortions in patients with fibroids is in agreement with results from earlier studies. ${ }^{6-10}$ The proposed mechanism is compressed endometrial vascular supply, affects the fetus adversely resulting in abortion. In our study, 2/42 $(4.76 \%)$ had pain abdomen, which is consistent with earlier studies.

Patients who suffered from pain due to fibroid in their antepartum period were $2(4.76 \%)$. This pain is due to red degeneration of fibroid which is common in pregnancy. Findings include focal pain, tenderness on palpation.

Treatment consists of analgesia and observation. Most often signs and symptoms are relieved within a few days in our study.

Though 3 (7.14\%) patients had preterm labor during pregnancy, rest of the patients had continued their pregnancy until term. The incidence of preterm delivery was $7.14 \%$ in our study which is inconsistent to Poovathi et al. $6(14.2 \%)$ had history of threatened abortion. ${ }^{5}$

Regarding the mode of delivery, 27 patients $(69.23 \%)$ had spontaneous onset of labor and vaginal delivery. Out of 39 patients, 12 had LSCS $(30.7 \%)$.

Lower segment cesarean section (LSCS) done in 12 $(30.7 \%)$ (Table 5). Indications for LSCS were breech presentation in $1(2.56 \%)$ women, 2 (5.12\%) women were with previous cesarean pregnancy, abruption placentae, $1(2.56 \%), 1(2.56 \%)$ placenta previa, $1(2.56)$ fetal distress and non-progressive labor in $2(5.12 \%)$ (Table 6). Even though the caesarean rate is higher, the presence of leiomyoma is not an indication to perform it.

In our study $4(10.25 \%)$ had $\mathrm{PPH}$, which is slightly low, compared with $18 \%$ in the study by Poovathi et al and $14 \%$ in the study by Lam et al. ${ }^{4,5}$

All $32(92.8 \%)$ babies were with weight above $2.5 \mathrm{~kg}$ with a good APGAR score (>7). Leiomyoma uteri usually don't affect fetal growth, but in our study women with leiomyoma were slightly at risk of delivering growth restricted $4(10.25 \%)$ and a low birth weight infant, 3 $(7.69 \%) .^{11}$

Neonatal outcomes were encouraging, thus indicating that fibroids do not impair fetal health so much. Women, who have fibroids detected in pregnancy, usually may require additional fetal surveillance when the placenta is implanted over or in close proximity to a fibroid because we know that, women with fibroids may deliver a growth-restricted infant. Rarely, very large fibroids can compress and distort the intrauterine cavity and thereby leading to fetal deformities. There was no perinatal and maternal mortality in our study.

\section{CONCLUSION}

Most of the fibroids are asymptomatic however they need frequent follow-up and evaluation as they may adversely affect the course of pregnancy and labor.

Fibroids complicating pregnancy lead to an increase in rate of caesarean section due to higher incidence of dysfunctional labor and malpresentation. The common antenatal complications were fetal growth restriction, malpresentation, spontaneous miscarriage, preterm labor, placenta previa. The occurrence of puerperal complications were low and most of the deliveries had uncomplicated perinatal outcomes.

Since these pregnancies are associated with increased incidence of cesarean delivery and PPH are considered as high risk.

\section{Funding: No funding sources}

Conflict of interest: None declared

Ethical approval: The study was approved by the Institutional Ethics Committee

\section{REFERENCES}

1. Cramer SF, Patel A. The frequency of uterine leiomyomas. Am J Clin Pathol. 1990;94:435-8.

2. Somigliana E, Vercellini P, Daguati R, Pasin R, De Giorgi O, Crosignani PG. Fibroids and female reproduction: A critical analysis of the evidence. Hum Reprod Update. 2007;13:465-76.

3. Qidwai GI, Caughey AB, Jacoby AF. Obstetric outcomes in women with sonographically identified uterine leiomyomata. Obstet Gynecol. 2006;107:37682.

4. James D, Steer PJ, Weiner CP, Gonik B, Robson SC, eds. High Risk pregnancy management options. 5th Edn. Cambridge University Press; 2018.

5. Sarwar I, Habib S, Bibi A, Malik N, Parveen Z. Clinical audit of fetomaternal outcome in pregnancies with fibroid uterus. J Ayub Med Coll Abbottabad. 2012;24:79-82

6. Lam SJ, Best S, Kumar S. The impact of fibroid characteristics on pregnancy outcome. Am J Obstet Gynecol. 2014;210:20.

7. Poovathi M, Ramalingam R. Maternal and foetal outcome in pregnancy with fibroids: a prospective study. Int J Sci Stud. 2016;3(11):169-72.

8. Katz VL, Dotters DJ, Droegemueller W. Complications of uterine leiomyomas in pregnancy. Obstet Gynecol. 1989;73:593-6.

9. Klatsky PC, Tran ND, Caughey AB, Fujimoto VY. Fibroids and reproductive outcomes: a systematic literature review from conception to delivery. Am J Obstet Gynecol. 2008;198:357-66. 
10. Koike T, Minakami H, Kosuge S, Usui R, Matsubara $\mathrm{S}$, Izumi A, et al. Uterine leiomyoma in pregnancy: Its influence on obstetric performance. J Obstet Gynaecol Res. 1999;25:309-13.

11. Gupta S, Manyonda IT. Acute complications of fibroids. Best Pract Res Clin Obstet Gynaecol. 2009;23:609-17.
12. Saha MM, Mondal D, Biswas SC. Pregnancy with leiomyoma uteri and feto-maternal outcomes. $\mathrm{Al}$ Ameen J Med Sci. 2016;9(2):96-100.

Cite this article as: Mhatre SD, Vazirani A, Selvam V. Prospective study to assess the obstetric and perinatal outcome in fibroid complicating pregnancy. Int J Reprod Contracept Obstet Gynecol 2021;10:1073-6. 